\title{
Sperm transfer and paternity in the scorpionfly Panorpa cognata: large variance in traits favoured by post-copulatory episodes of sexual selection
}

\author{
Leif Engqvist • Gabriele Dekomien · Tanja Lippmann • \\ Jörg T. Epplen · Klaus P. Sauer
}

Received: 4 September 2006/ Accepted: 13 December 2006/ Published online: 2 February 2007

(C) Springer Science+Business Media B.V. 2007

\begin{abstract}
Post-copulatory episodes of sexual selection can be a powerful selective force influencing the reproductive success of males. In order to understand variation in male fertilisation success, we first need to consider the pattern of sperm utilisation by females following matings with more than one male. Second, we need to study those traits responsible for male success in sperm competition. Here we study both male sperm transfer characteristics as well as offspring paternity of females mated to two males in the scorpionfly Panorpa cognata. By repeatedly mating males to virgin females and interrupting copulation at defined time points, we found for all males that sperm transfer set off after approximately $40 \mathrm{~min}$. During the remaining copulation, sperm transfer of individual males was continuous and with constant rate. Yet the rate of sperm transfer differed between individual males from about one sperm per minute to more than eight sperm per minute for the most successful males. In addition, we measured the fertilisation success in sperm competition of males with known sperm transfer capability. The relative number of sperm transferred by males during copulation, estimated from copulation duration and the males' individual sperm transfer rate, explained a large proportion of variation in offspring paternity. The mode of sperm competition in this species, thus, conforms largely to a fair raffle following complete mixing of sperm prior to fertilisation. Hence, male differences in both the ability to copulate for long and of rapid sperm transfer will translate directly into differences in reproductive success.
\end{abstract}

Keywords Copulation duration $\cdot$ Cryptic female choice $\cdot$ Fair raffle $\cdot$ Mecoptera $\cdot$ Microsatellites $\cdot$ Sperm competition $\cdot$ Sperm precedence

L. Engqvist $(\bowtie) \cdot$ K. P. Sauer

Department of Evolutionary Biology and Ecology, University of Bonn, An der Immenburg 1, 53121 Bonn, Germany

e-mail: lengqvist@evolution.uni-bonn.de

G. Dekomien · T. Lippmann · J. T. Epplen

Human Genetics, Ruhr-University,

Bochum, Germany 


\section{Introduction}

In species in which females mate with several males, male reproductive success will not only be restricted by their access to female mating partners, but also by the success of their sperm in the subsequent competition for fertilisations (Parker 1970; Eberhard 1996; Birkhead and Møller 1998; Simmons 2001). It is well established that in case of female double or multiple mating, individual males differ considerably in their paternity success, measured as the proportion of offspring that is sired by their sperm (Lewis and Austad 1990; Dziuk 1996; Radwan 1996; Gage and Morrow 2003), and that this ability may to some extent be heritable (e.g. Radwan 1998; Froman et al. 2002; Gage and Morrow 2003). This fact prompts the question which traits determine male success in sperm competition and are responsible for this inter-individual variance. Males' sperm may differ in motility (e.g. Birkhead et al. 1999; Gage et al. 2004), size (e.g. Ward 1998; Morrow and Gage 2001) or longevity (Gage et al. 1995), and these factors may all influence the probability that their sperm will fertilise the females' eggs (review in Snook 2005). Nevertheless, it is obvious that the outcome of sperm competition is in many cases mediated largely by the relative numbers of sperm from competing males (e.g. Parker 1982; Dickinson 1986; Parker et al. 1990; Eady 1995; Dziuk 1996; Simmons 2001; Gage and Morrow 2003).

The importance of high sperm numbers, however, is largely influenced by the pattern of sperm utilisation following mating with several males. If for instance sperm is stored by females in specific storage organs, as is the case in most insect species, mating order may have a considerably effect on realised paternity (for a review see for instance Simmons and Siva-Jothy 1998). In some species, males are able to plug the entrance to the storage organ preventing the sperm transfer from future rival males (e.g. Baer et al. 2001; Polak et al. 2001). More commonly, the latest male to mate can be able to displace parts of, or completely remove, the sperm masses from previous males (e.g. Waage 1979; Gack and Peschke 1994). Even when the sperm from different males are fully represented in females' sperm storage organ prior to fertilisation, sperm stratification or incomplete sperm mixing (see for instance Harvey and Parker 2000) may obstruct sperm competition on a numerical basis. In insects where the sperm storage organ, the spermatheca, is usually placed at the dead end of a spermathecal duct, this may favour the last male to mate (Walker 1980; Birkhead and Hunter 1990; Simmons and Siva-Jothy 1998). The effect of mating order on the outcome of sperm competition-usually referred to as $P_{2}$, the proportion of offspring sired by the last of two males to mate (Boorman and Parker 1976)—will have considerable consequences for the selection on associated male traits. Last male sperm precedence is, for instance, assumed to favour male post-copulatory mate guarding behaviour (Alcock 1994; Simmons and Siva-Jothy 1998). Most importantly for the present study, the degree of sperm precedence will also have profound effects on the importance of high sperm numbers for fertilisation success. It is obvious that when males are able to remove foreign sperm, direct sperm competition is prevented and males may sire the majority of offspring irrespective of sperm number. With an increasing magnitude of sperm mixing, the importance of large sperm numbers will increase, and will be highest when a fair raffle of sperm will precede fertilisation (Parker et al. 1997; Engqvist and Reinhold 2006). Therefore, 
in order to fully understand variation in male fertilisation success and variation in the responsible traits, it is important to understand the mode of sperm use that follows female multiple mating as complete as possible. In this study, we studied sperm precedence patterns and the influence of male sperm transfer ability on male fertilisation success in the scorpionfly Panorpa cognata (Ramb.) (Insecta: Mecoptera).

Panorpa scorpionfly mating systems have been extensively studied (e.g. Thornhill 1981; Gerhards and Sauer 1997; Sauer et al. 1998; Gerhards et al. 1999; Aumann 2000; Engqvist and Sauer 2003b; Kock et al. 2006). Scorpionfly males provide females with nutritious salivary secretions and females feed on these nuptial food gifts during copulation (Byers and Thornhill 1983; Sauer et al. 1998; Engqvist and Sauer 2003b; Kock et al. 2006). In a number of species, it has been shown that the duration of copulations will depend on the amount of saliva a male presents (Gerhards and Sauer 1997; Sauer et al. 1998; Engqvist and Sauer 2001). Furthermore, sperm is transferred continuously during copulation (Sauer et al. 1997; Gerhards et al. 1999; Engqvist and Sauer 2003a). Thus proximately, male sperm transfer during copulation will be affected by male ability to present females with a large amount of secretion (Sauer et al. 1998; Engqvist and Sauer 2001, 2003a). The mode of sperm competition has in detail been described for P. vulgaris (e.g. Sauer et al. 1990, 1998, 1999), and recently also for $P$. germanica (Kock et al. 2006). In these species and in $P$. cognata, female sperm storage organs consist of a long, narrow spermathecal duct which is followed by a single, kidney-shaped spermatheca, where all sperm is stored. The sperm storage capacity of the spermatheca by far exceeds the number of sperm that is transferred during a single copulation (cf. Sauer et al. 1997, 1999). During copulation, males inject sperm into the females' spermatheca by the contractions of a sperm pump (cf. Grell 1942; Sauer et al. 1997). The studies on P. vulgaris have suggested a fair sperm raffle following complete mixing of sperm from different males in the female's spermatheca prior to fertilisation. Thus in P. vulgaris, which is a promiscuous species, a male's lifetime reproductive success will largely be determined by his lifetime copulation duration (Sauer et al. 1998). Results of studies on $P$. germanica suggest a much more incomplete mixing and a slight advantage for the last male to mate (Kock et al. 2006). Nevertheless, copulation duration and, thus, sperm amount transferred will affect a male's fertilisation chances in the subsequent raffle.

In $P$. cognata males offer one large salivary mass prior to the copulation and its size will affect copulation duration (Engqvist and Sauer 2001). A previous study has shown that males differ considerably in their capability to transfer sperm during copulation. Yet these differences do not solely depend on male differences in their ability to produce large salivary secretions and, hence, on differences in copulation duration. In addition, males differ significantly in the number of sperm they transfer per unit time (Engqvist and Sauer 2003a). An immediate cause for this variation is not known. Principally, variation in male sperm transfer ability may be explained by 1. male variation in the time of onset of sperm transfer (Fig. 1a), 2. male variation in sperm transfer rate sensu stricto (Fig. 1b), or 3. both (Fig. 1c). The differentiation between these possibilities is important because they differ in the way copulation duration will influence male sperm transfer (cf. Fig. 1). The first aim of this study was therefore to study the dynamics of sperm transfer during copulation in order to better understand the factors affecting male variance in sperm transfer. Second, we 

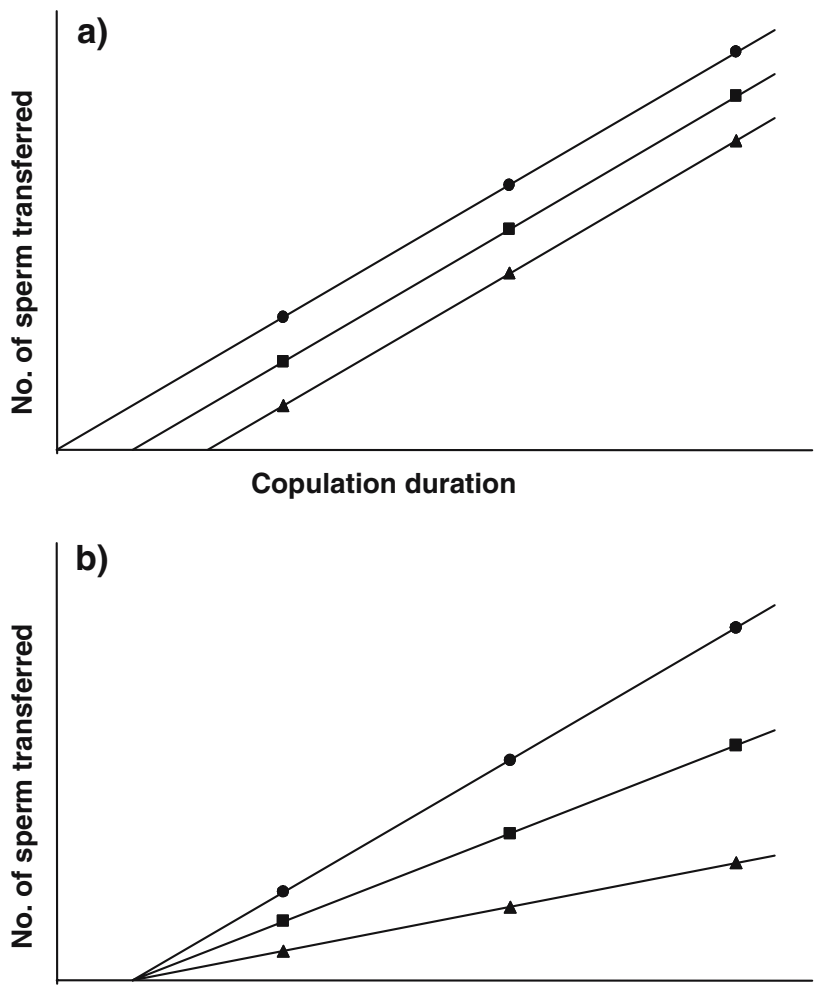

\section{Copulation duration}

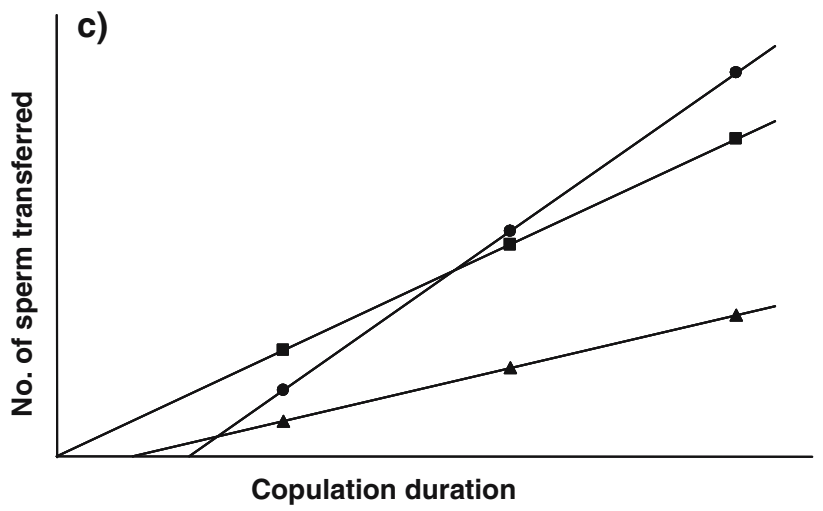

Fig. 1 Theoretical examples on how variance in male sperm transfer rate can be explained by differences in male sperm transfer parameters: (a) males differ in the onset of sperm transfer only but not regarding the rate of sperm transfer, (b) the time for the onset of sperm is identical for males but they differ in the rate of sperm transfer, (c) males differ both regarding the onset of sperm transfer and the rate of sperm transfer

studied the pattern of sperm precedence and female sperm utilisation in order to determine to which extent these differences in males' sperm transfer ability affect male fertilisation success in sperm competition. 


\section{Materials and methods}

Breeding and mating trials

All animals used in these experiments were $F_{1}$ offspring from animals caught near Freiburg in Breisgau in south-western Germany and bred using standard breeding protocols (see e.g. Sauer 1977; Thornhill and Sauer 1992; Engqvist and Sauer 2003b). All adult males and females used in the experiments were held individually in small plastic cylinders $(8 \times 3.5 \mathrm{~cm})$ containing moist filter paper and food. Adult diets were standardised and consisted of a one-segment piece of last instar mealworm (Tenebrio molitor) every third day ( $c f$. Engqvist and Sauer 2001, 2003a). All mating trials were staged in plastic boxes $(10 \times 10 \times 7 \mathrm{~cm})$ containing moist tissue papers and a piece of stem and leaf of a nettle plant (Urtica dioica) but no food. Like many scorpionflies, $P$. cognata is crepuscular and nocturnal in its mating activities (Thornhill 1981; Byers and Thornhill 1983; Engqvist and Sauer 2003b). Females approach pheromone emitting males almost exclusively during the last hours prior to nightfall and mate during night (Engqvist and Sauer 2003b). We therefore performed all mating trials under a reversed day/night cycle starting the trials approximately five hours prior to the dark phase (see Engqvist and Sauer 2003b).

\section{Measuring variance in individual male sperm transfer rate}

Eighteen unrelated and well fed males (that had received a one-segment piece of a mealworm every third day) were chosen for the experiment. Only sexually mature males that were obviously emitting pheromones and thus 'calling' for females were used (see also Thornhill 1979; Engqvist and Sauer 2003b). Furthermore, since female weight and hence condition has an influence on male sperm transfer rate in $P$. cognata (Engqvist and Sauer 2003a), only females with body weights ranging from $47.5 \mathrm{mg}$ to $52.5 \mathrm{mg}$ were chosen for the mating trials.

All males used in the experiment were mated at least three times: once for one hour, once for two hours, and once for three hours. This yields six different combinations of mating orders and males were randomly assigned to mate in a specific order. One virgin female and one male were randomly put together in each box. We recorded the precise beginning of the matings and all copulations were interrupted following a predetermined scheme after 60,120 or 180 min by gently touching the copulating pair. Only one mating trial per male was performed each day. Mating trials, in which males failed to mate or copulated shorter than the required time were repeated on the next day with a new female.

\section{Spermatheca dissection and sperm counts}

Following copulation, mated females were killed under $\mathrm{CO}_{2}$-anaesthesia and sub-

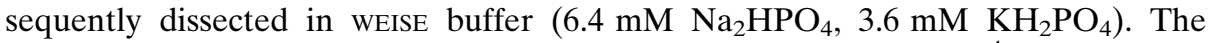
spermatheca was carefully removed and placed in a droplet of a $10^{-4} \mathrm{M}$ solution of the DNA-specific fluorochrome 4',6-diamidino-2-phenylindole (DAPI, Sigma) on a glass slide (see also Sauer et al. 1997; Engqvist and Sauer 2003a). Using fine needles, the chitinous spermatheca was ruptured, and the released sperm was cautiously spread. Following addition of a drop of glycerine, the slide preparations were 
mounted with coverslips and stored in a refrigerator until microscopic evaluation. Spermatozoa were counted using a fluorescence microscope at 200-400 $\times$ magnification. Because of their specific shape, sperm nuclei could easily be distinguished from somatic nuclei.

Statistical analysis

Statistical analyses were performed with R 2.1.0 (Ihaka and Gentleman 1996). We used mixed effects linear models (Pinheiro and Bates 2000) to analyse the random effect of male and the fixed effect of copulation duration on variation in number of sperm transferred. Sperm transfer rate has been shown to be highly repeatable across male matings (Engqvist and Sauer 2003a), and thus the effect of male mating number seems negligible. Besides, we controlled female weight experimentally. Nevertheless, we included male mating number and female weight in the initial analyses in order to control for potential error variance. As expected, neither male mating number $\left(F_{2,20}=1.36 ; P=0.28\right)$ nor female weight $\left(F_{1,20}=0.07 ; P=0.78\right)$ had an influence on sperm transfer and we therefore removed them prior to further analyses. Parameter values were based on restricted maximum likelihood estimates. Tests on random effects were based on likelihood ratios, which follow a $\chi^{2}$-distribution.

\section{Measuring variance in paternity}

In this experiment, all females mated with two males. Males were randomly assigned to either mate first or second with a female. Initial matings with a female's first male were repeated each day until the female had mated. After females had mated, they were remated the next day, to another male. As with the females' first matings, these second mating trials were repeated each day until the female had mated twice. The mean \pm SD time interval between initial and second mating amounted to $2.71 \pm 2.74$ days (range: $1-14$ days). In all matings, the duration of copulations was recorded.

Doubly mated females were held individually in oviposition boxes (provided with a peat-filled petri dish for egg laying and with food ad libitum). Boxes were checked daily for eggs laid. Mean \pm SD oviposition time lag of females was $4.67 \pm 1.94$ days (range: 1-9 days). As female remating interval and oviposition time lag will influence the difference in sperm age between first and second males, and thus possibly influence sperm precedence, these factors were included as covariates in the subsequent analyses. Eggs were carefully transferred from the egg-laying petri dish to a new petri dish containing moist tissue paper. Egg batches were covered with another layer of moist tissue paper and subsequently incubated at $18^{\circ} \mathrm{C}$ and an $18: 6 \mathrm{~h}$ light:dark photoperiod. Mean \pm SD hatching success amounted to $0.59 \pm 0.20$. Hatched first instar larvae were immediately transferred into Eppendorf tubes and held at $-80^{\circ} \mathrm{C}$ until DNA extraction and paternity analysis. Similarly, all males and females used for the mating trials were stored at $-80^{\circ} \mathrm{C}$.

Estimation of male sperm transfer rate

The amount of sperm transferred by males will be dependent on both copulation duration and the male's sperm transfer ability. It is, at present, impractical to 
simultaneously measure the paternity of female offspring and the number of sperm initially transferred by different males to the female. We therefore attempted to estimate male individual sperm transfer ability from standardised mating trials. Sperm transfer rate of males have been shown to be highly repeatable across matings and mating number has no noticeable effect (Engqvist and Sauer 2003a). Therefore, all males used as mates in the previously described doubly mating trials were subsequently mated to a virgin female for exactly $120 \mathrm{~min}$. Subsequently, the number of sperm transferred was determined as in the previous experiment. Female condition has been shown to influence male sperm transfer rate (Engqvist and Sauer 2003a). As in the first experiment, we therefore controlled for this effect experimentally by confining the weight of the chosen females to be within $47.5-52.5 \mathrm{mg}$. The small residual variance in female condition did not significantly influence male sperm transfer rate $\left(\beta=14.1 \pm 25.6 \mathrm{sperm} / \mathrm{mg} ; r=0.081 ; t_{46}=0.55 ; P=0.58\right)$

DNA extraction and microsatellite analysis

The DNA of adults and first instar larvae was extracted using the standard protocol of an isolation kit (Nucleo Spin Tissue, Machery \& Nagel). Paternity was determined using four polymorphic microsatellite loci. Two microsatellites (Pc4 and Pc6) were identified in P. cognata DNA using standard procedures (Epplen et al. 1998; Lubjuhn and Sauer 1999). The two other systems (Pcm3 and Pcm15) have been developed for the related species $P$. communis (Siegmund 2006), but the primers also showed efficient annealing in $P$. cognata. The $P c 4$-locus comprises a $(\mathrm{CCT})_{\mathrm{n}}$ repeat, and primers for its amplification were 5Pc4: 5'-ACA ATG GTG TCG CAG CTC ACC-3' and 3Pc4: 5'-CTA CGC CGT CAC CGT CTG GTG-3'. The Pc6-locus contains a $(\mathrm{AT})_{\mathrm{n}}$ repeat, and primers for amplification were 5Pc6: 5'-GCT GTG ATA ACA TCA GTT TCG CAT and 3Pc6: 5'-CCT TTG GTG TGC CGA GAC ACT. The forward primers were fluorochrome labelled for automatic fragment sizing of PCR products on an ABI 377 sequencer, utilising the GeneScan software program. The primers $5 \mathrm{Pcm} 15$ and $5 \mathrm{Pc} 4$ were $\mathrm{HEX}$ labelled and $5 \mathrm{Pcm} 3$ and $5 \mathrm{Pc} 6$ FAM labelled. For each DNA sample PCR reactions contained 50-100 ng DNA, $1 \times$ PCR buffer Y (Peqlab), $2 \times$ Enhancer Solution S (Peqlab), $200 \mu \mathrm{M}$ dNTPs, 3 pmol of each primer and $0.25 \mathrm{U}$ Taq polymerase (Peqlab), and were performed in a T1 thermocycler (Biometra). The initial denaturing time was $5 \mathrm{~min}$ at $94^{\circ} \mathrm{C}$, thereafter $1 \mathrm{~min}$ for 5 cycles and $30 \mathrm{~s}$ for another 30 cycles. Annealing time was $1 \mathrm{~min}$. Annealing temperature was $57^{\circ} \mathrm{C}$ for $P c m 3$ and $P c m 15,58^{\circ} \mathrm{C}$ for $P c 6$ and $60^{\circ} \mathrm{C}$ for $P c 4$. Elongation lasted $1 \mathrm{~min}$ at $70^{\circ} \mathrm{C}$ in every cycle and $5 \mathrm{~min}$ at $72^{\circ} \mathrm{C}$ in the final step.

Adults were pre-screened and the most informative locus was used for paternity assignment. In a few cases, the paternity of all offspring within a clutch could not be assigned unambiguously using one locus. For these offspring, other loci were employed in order to unequivocally determine the male sire.

Statistical analysis

Paternity success of males was analysed with a Generalized Linear Model (GLIM) with binomial errors linked to a logit function (see e.g. Venables and Ripley 2002). Our aim was to estimate the influence of copulation duration and sperm transfer rate on male fertilisation success. Per definition, sperm transfer rate cannot have an 
additive effect on sperm amount transferred, independent of copulation duration. Rather copulation duration and the rate of sperm transfer will act multiplicatively on sperm amount and prospective paternity success. Instead of a more conventional model with additive effects, we therefore used a multiplicative model where sperm amount is described by the copulation duration $\times$ sperm transfer rate interaction term. Paternity may also be influenced by the age of the first male's sperm in relation to the age of the second male's sperm. We therefore included female remating interval and oviposition time lag as covariates in our analyses.

Bias in sperm use can be modelled by introducing a loading factor $(r)$, which describes the relative advantage/disadvantage of the second male's sperm $\left(P_{2}=r \times s_{2} /\left(r \times s_{2}+s_{1}\right)\right)$ (Parker et al. 1997). Thus $r>1$ represents second male sperm precedence, $r<1$ first male sperm precedence and $r=1$ a fair raffle of sperm. We used maximum likelihood estimation for the mean and confidence limits of $r$. The maximum likelihood estimate of $r$ will maximise the log likelihood function

$$
\sum\left(O_{i 1} \ln \left(1-\hat{p}_{i 2}\right)+O_{i 2} \ln \left(\hat{p}_{i 2}\right)\right)
$$

where $O_{i 1}$ and $O_{i 2}$ gives the observed number of female $i$ 's offspring that were sired by the first and second male respectively, and $\hat{p}_{i 2}$ the model's expected proportion of offspring sired by the second male.

\section{Results}

Variance in individual male sperm transfer

Of the 18 males that were assigned to the experiment, 13 males successfully completed the three required copulations. In addition, one dissection failed, as the spermatheca was ruptured in the buffer solution, leaving a total of 36 sperm transfer estimates from twelve males.

As expected, copulation duration had a significant effect on number of sperm transferred (repeated measures ANOVA: $F_{2,10}=21.3 ; P<0.001$; Fig. 2 ). The mean $\pm \mathrm{SD}$ number of sperm transferred was $108.0 \pm 47.8$ after $60 \mathrm{~min}$, $345.8 \pm 167.3$ after $120 \mathrm{~min}$ and $622.1 \pm 289.2$ after $180 \mathrm{~min}$. A linear mixed-effect model including the random effects of male individual for both intercept and slope revealed a highly significant effect of copulation duration on number of sperm transferred (slope $=4.28 \pm 0.63 \mathrm{sperm} / \mathrm{min} ; t_{23}=6.83 ; P<0.0001$ ). Furthermore the intercept differed significantly from zero (intercept $=-155.4 \pm 38.6$ sperm; $\left.t_{23}=-4.02 ; P=0.0005\right)$, indicating that the onset of sperm transfer on average does not coincide with the beginning of copulation. The between-male variability was estimated to $2.07 \mathrm{sperm} / \mathrm{min}$ (SD) for the transfer rate (slope) and to 96.9 sperm for the intercept. Both these random effects significantly improved the model (likelihood ratio test (LRT): sperm transfer rate (slope), $\chi^{2}=32.7 ; d f=2 ; P<0.0001$; intercept, $\left.\chi^{2}=8.7 ; d f=2 ; P=0.01\right)$. Thus, there is significant variability between males with respect to their sperm transfer rate and the intercept at $x=0$ min (Fig. 2a). Yet, as the onset of sperm transfer does not coincide with the beginning of copulation, the variation in zero-intercept gives us little information on the between male variability of this trait. Instead the extrapolation from the true onset of sperm transfer $(x>0)$ back to copulation begin $(x=0)$ resulted in a strong negative 

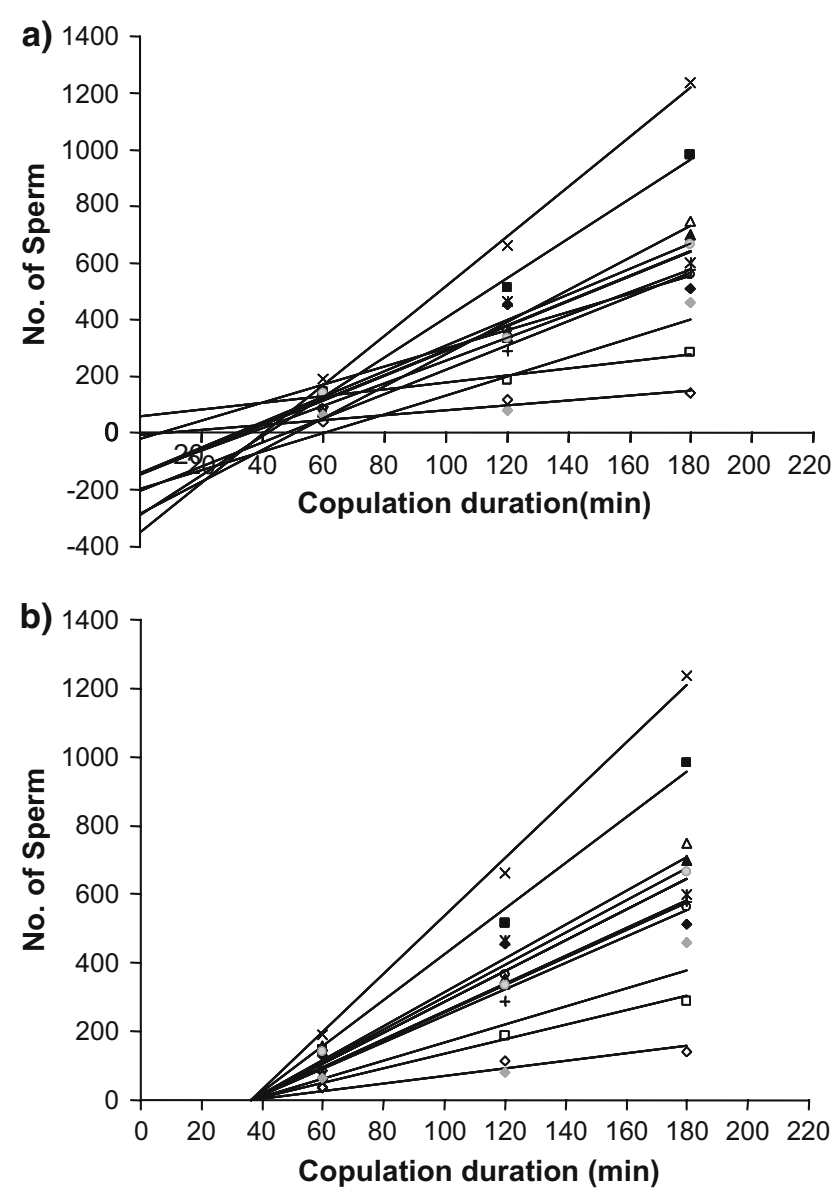

Fig. 2 Relationship between copulation duration and sperm transfer for twelve different males. (a) shows the model assuming individual differences in both sperm transfer rate (slope) and onset of sperm transfer, whereas (b) shows the most parsimonious model, with individual differences in sperm transfer rate but no difference in the onset of sperm transfer

correlation $(r=-0.981)$ between the slope estimates and their corresponding estimates of the zero-intercept (see Fig. 2a and $c f$. Pinheiro and Bates 2000, p. 34). We removed this effect by fitting the number of sperm transferred as a linear function of the hypothetical effective mean sperm transfer time. This was calculated by subtracting the mean delay of sperm transfer, $36.3 \mathrm{~min}[-($ mean intercept $) /$ mean slope $=155.4 / 4.28$ ], from the actual copulation duration. This model of course gave the same fixed effect estimate for the slope $(4.28 \mathrm{sperm} / \mathrm{min})$, but differed with regard to the intercepts and the random effect estimate from the original model. The random effect estimate for the slope was slightly reduced to $2.03 \mathrm{sperm} / \mathrm{min}$. Yet the estimated between male variance in intercept was now considerably reduced compared to the first model to 20.8. Inclusion of random effect slopes still significantly improved the model (LRT: $\chi^{2}=32.8 ; d f=2 ; P<0.0001$ ), but not the inclusion of the random intercept (LRT: $\chi^{2}=0.6 ; d f=2 ; P>0.7$ ). We therefore conclude that 
the simpler model without random male effects regarding the onset of copulation is sufficient to describe male variance in sperm transfer rate (Fig. 2b).

Thus in conclusion, sperm transfer dynamics in $P$. cognata can simplest be described by two processes: delay of sperm transfer followed by continuous sperm transfer. Begin of sperm transfer was on average after 36.3 min and similar for all males. The $95 \%$ confidence interval, for the time of sperm transfer begin, was estimated to 22.3-46.6 min. Sperm transfer rate, in the strict sense, showed significant inter-individual variance. Average \pm SD male sperm transfer rate was $4.28 \pm 2.03 \mathrm{sperm} / \mathrm{minute}$. The estimated sperm transfer rate for the males in our sample ranged from $8.42 \mathrm{sperm} / \mathrm{min}$ for the most efficient male to $1.09 \mathrm{sperm} / \mathrm{min}$ for the least successful male.

\section{Variance in paternity}

Overall, 24 doubly mated females were included in the paternity analyses. These 24 females had mated with 48 different males, for which sperm transfer rate had been successfully determined. In each family, paternity was determined for 17 randomly chosen first instar larvae.

Copulations durations ranged between 70 and 296 min. Overall, the mean \pm SD copulation duration was $170.1 \pm 63.0 \mathrm{~min}$ and was not significantly different between males mating first or males mating second (first male: $169.1 \pm 68.0 \mathrm{~min}$; second male: $172.9 \pm 70.7$ min; paired $t$-test $\left.: t_{23}=0.16 ; P=0.8\right)$. The mean \pm SD sperm transfer rate of males amounted to $452 \pm 182 \mathrm{sperm} \times(120 \mathrm{~min})^{-1}$ and ranged between 80 and $766 \mathrm{sperm} \times(120 \mathrm{~min})^{-1}$. Sperm transfer rate was not significantly different between males assigned to mate first or second (first male: $429 \pm 197$; second male $473 \pm 145$ sperm $\times(120 \mathrm{~min})^{-1}$; paired $t$-test $\left.: t_{23}=0.92 ; P=0.37\right)$.

The copulation duration of both the first male and the second male significantly influenced paternity distribution (Table 1, Fig. 3a). Specifically, longer copulations of the second male will increase its fertilisation success, whereas longer copulations of the first male will decrease it (and increase the success of the first male). The proportion of deviance explained by this model was $21.9 \%$. Moreover, the hypothetical sperm amount transferred by males, given statistically by the multiplicative copulation duration $\times$ sperm transfer rate interaction term, significantly influenced male paternity success (Table 1, Fig. $3 b$ ). Including male sperm transfer rate significantly reduced the residual deviance (LRT: $\chi^{2}=47.3 ; d f=2 ; P<0.001$; proportion of deviance explained: $66.2 \%$ ). Thus, both copulation duration and male sperm transfer rate influence a male's fertilisation success. But copulation duration has no additional effect on paternity once its affect on sperm transfer has been accounted for (Table 1). In both models, neither female remating interval nor female oviposition time lag had a significant effect on sperm precedence (Table 1).

In our sample, $P_{2}$-values range from 0 to 0.94 . The overall $P_{2}$-estimate in our analysis equalled 0.556 . Yet, as copulation durations and sperm transfer rates were slightly higher for the second males compared to the first males to mate, this estimate is slightly biased. In order to compare our data with different levels of sperm precedence, we calculated the hypothetical sperm amount transferred by all males based on copulation duration and individual sperm transfer rate. Taking this into account, one would expect a $P_{2}$-value of 0.517 even when assuming a complete fair raffle of sperm. The distribution of paternity between the first and the second male 
Table 1 Estimated effects of copulation duration of first and second males, remating interval and oviposition time lag on fertilisation success. Model 2 additionally includes the effect of the estimated sperm amount transferred by the first and second male. The $\beta$-values give the slope of the log-odds ratio $\left(\times 10^{-3}\right)$, where the odds refer to the fertilisation probability of the second male. Thus, the sign of the slope gives the direction of the effect on the second male's share of paternity. The $\chi^{2}$-values of the likelihood ratio tests give the changes in deviance when compared to models without the respective parameters

\begin{tabular}{llrcc}
\hline & Predictor variables & $\beta \pm \mathrm{SE}$ & $\chi^{2}{ }_{1}$ & $P$ \\
\hline Model 1 & Copulation duration 1st (min) & $-6.95 \pm 2.15$ & 10.9 & 0.001 \\
& Copulation duration 2nd (min) & $11.4 \pm 2.67$ & 21.2 & $<0.0001$ \\
& Remating interval (days) & $-62.6 \pm 42.7$ & 2.25 & 0.13 \\
& Oviposition lag time (days) & $-76.1 \pm 58.0$ & 1.72 & 0.18 \\
Model 2 & $4.56 \pm 3.80$ & 1.50 & 0.232 \\
& Copulation duration 1st (min) & $-6.38 \pm 5.05$ & 1.60 & 0.21 \\
& Copulation duration 2nd (min) & $-1.65 \pm 0.48$ & 13.0 & 0.0003 \\
& Sperm amount estimate 1st (Copulation & & & \\
& $\quad$ duration $\times$ Sperm transfer rate) & $3.68 \pm 0.80$ & 23.1 & $<0.0001$ \\
& Sperm amount estimate 2nd (Copulation & & & \\
& $\quad$ duration $\times$ Sperm transfer rate) & $-27.4 \pm 44.2$ & 0.39 & 0.53 \\
& Remating interval (days) & $-27.1 \pm 65.1$ & 0.17 & 0.68 \\
\hline
\end{tabular}

did not differ significantly from the hypothetical distribution assuming a fair raffle (LRT: $\chi^{2}=2.88 ; d f=1 ; P=0.09$ ). The distribution of paternity differed significantly from a fair raffle in three families, but this is not unexpected, given that we analysed 24 families. Furthermore, the distribution of paternity was not significantly heterogeneous over different families (LRT: $\chi^{2}=31.6 ; d f=23 ; P>0.2$ ). The maximum likelihood estimate of the loading factor $r$ was 1.20 (95\% CI: $0.93-1.55)$, which corresponds to a $P_{2}$-value of 0.545 (95\% CI: $\left.0.482-0.608\right)$.

\section{Discussion}

This study has focused on the causes of variance in male reproductive success when females have mated with more than one male in the scorpionfly Panorpa cognata. It has been demonstrated that the number of sperm transferred by males during copulation will strongly affect a male's fertilisation success (Fig. 3b), and that the mode of sperm competition does not differ considerably from a fair raffle of sperm. Nevertheless, the residual variance in fertilisation success not explained by sperm number is non-trivial and there is slight, though non-significant, bias in paternity towards the second male to mate. Therefore, at present, slight deviations from complete sperm mixing cannot definitely be ruled out. The number of sperm that a male is able to transfer during copulation will be determined by at least two processes, (1) the duration of copulation and (2) the male's individual sperm transfer rate (Fig. 2). Thus, as sperm compete numerically, both copulation duration and sperm transfer rate will positively affect a male's paternity success. The observed correlation between relative copulation duration and paternity thus suggests mixing of sperm from both males inside the female's spermatheca. Therefore, these observations are also in accordance with the 'sperm-loading' hypothesis (Dickinson 1986), which proposes that prolonged copulations will enhance the competitive ability of an ejaculate by increasing sperm numbers provided sperm is transferred 

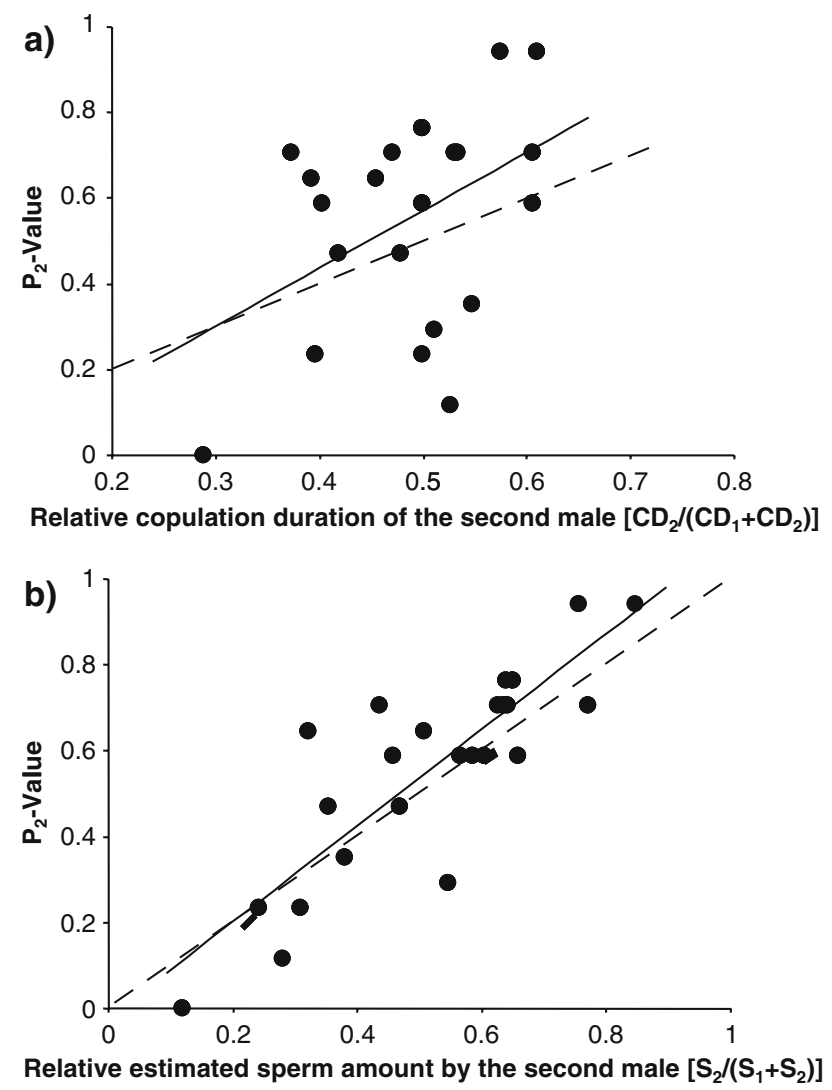

Fig. 3 Illustrations showing the effect of (a) relative copulation duration of the second male to mate on $P_{2}$ - the relative fertilisation success of the second male and (b) the effect of the relative sperm amount transferred by the second male on $P_{2}$. Sperm amount is estimated from the copulation duration and the sperm transfer rate of males that were determined in control copulations with virgin females. For this purpose, the most parsimonious equation describing sperm transferred $(s)$ as a function of copulation duration (cd) and sperm transfer rate (sr) was used: $s=(\mathrm{cd}-36.3 \mathrm{~min}) \times \mathrm{sr}$. The dashed lines depict the expected outcome, assuming that the sperm from the second male to mate have equal fertilisation chances as the sperm from the first male. Solid lines give the least square regression

continuously throughout copulation (see also Dickinson 1986; Tsubaki and Sokei 1988; Parker et al. 1990; Eady 1995; Sauer et al. 1997, 1998; Kock et al. 2006).

The slight overall bias in paternity towards the second male to mate might reflect a sperm stratification effect through a 'last-in-first-out'-mechanism. This could lead to a preferential use of last males' sperm (Walker 1980; Birkhead and Hunter 1990; Simmons and Siva-Jothy 1998). High $P_{2}$-values can also be the result from death or loss of sperm, which would to a greater extent affect first males' sperm (Tsubaki and Yamagishi 1991). Yet differences in sperm age between first and second males do not seem to have had a large influence in the present study, as neither the female remating interval nor the oviposition time lag had any detectable effect on male sperm precedence (Table 1). Another possibility is that males detect female mating status and adjust sperm allocation according to it (for instance Cook and Gage 1995; 
Wedell 1998; Martin and Hosken 2002; Siva-Jothy and Stutt 2003). Estimates of sperm transfer rates were made in matings with virgin females. This will be an underestimate of the true sperm transfer if male sperm investment is increased in copulations with non-virgin females in response to a higher sperm competition risk. As a consequence, the estimate of sperm precedence will be biased towards the second male (see discussion in Engqvist and Reinhold 2006). Similarly, the second males' sperm amount seems to affect the outcome of sperm competition stronger than the first males' sperm amount (see Table 1). A possibility is that the between male variability in sperm transfer rate is amplified in matings with already mated females.

The present study confirms a previous study on $P$. cognata demonstrating large inter-individual variability in male sperm transfer ability (Engqvist and Sauer 2003a). By measuring the sperm amount transferred by the same individuals after discrete time intervals, it was now possible to resolve the functional source of this variation. Males differ considerably regarding the rate of sperm transfer but not with respect to the onset of sperm transfer. The ultimate cause for this variation remains to be clarified. As this is closely linked to male reproductive success, deviations from an optimal sperm transfer rate imply male constraints on sperm transfer. Males inject sperm into the females' spermatheca by the contractions of a sperm pump (Grell 1942; Sauer et al. 1997; Engqvist and Sauer 2003a). The large size of the muscles connected to this pump (cf. Grell 1942) suggests that sperm transfer in scorpionflies may need considerable force. Males appear to change the rate of sperm transfer according to the quality of females (Engqvist and Sauer 2003a), supporting the view that sperm transfer is costly to males. Yet phenotypic indices of male condition seem to be only weakly associated with male sperm transfer rate (Engqvist and Sauer 2003a). Alternatively, constraints may be manifested during larval growth. For instance, there may be a trade-off between resources allocated to sperm pump development and other important traits. For other insects, it has been shown that cues signalling future sperm competition risk and intensity during development may considerably change resource allocation to sperm competition relevant traits (Cook and Gage 1995; Stockley and Seal 2001). As a result, males may be differently suited for sperm competition. In a supplementary study (L. Engqvist, unpublished data) it was demonstrated that there is considerable genetic variance underlying the phenotypic variance in male sperm transfer rate.

In addition to the ability to transfer sperm at a fast rate, copulation duration will strongly affect the amount of sperm a male transfers during copulation (Fig. 2). During mating, females feed on a salivary mass that is secreted by the male. Almost invariably, copulations are terminated by females immediately after the females have consumed the salivary mass (Engqvist and Sauer 2003b). Copulation duration and sperm transfer will thus be affected by the ability of males to secrete a large salivary mass prior to copulation (Engqvist and Sauer 2001). Hence, female termination of copulations following saliva consumption can be seen as an expression of cryptic female choice (sensu Thornhill 1983). This behaviour in concert with continuous sperm transfer and sperm mixing will allow females to allocate paternity in proportion to male ability to secrete a large amount of saliva (see e.g. Sakaluk and Eggert 1996; Sauer et al. 1998 for similar studies). This effect will be reinforced by the time delay of sperm transfer (see Fig. 2), as this will primarily penalise males that secrete small salivary masses. Previous studies have demonstrated a robust association between male condition, salivary gland size, and male ability to produce large 
salivary masses and copulate for long periods (Engqvist and Sauer 2001, 2003a). Thus, this mechanism of sperm competition will favour high quality males. In this respect $P$. cognata shows conspicuous similarities to the extensively studied mating system of P. vulgaris (Sauer 1996; Sauer et al. 1997, 1998, 1999) and also to P. germanica (Kock et al. 2006).

In this study we have examined some of the mechanisms responsible for male fertilisation success following female mating with more than one male. It has unravelled large male variance in traits affecting male success in sperm competition. Future research in this system aiming to further analyse the ultimate causes for male variance seem promising in order to increase our understanding of the post-copulatory components of sexual selection.

Acknowledgments We thank Dagmar Kock, Merle Missoweit and two anonymous reviewers for valuable comments on the manuscript. This study was supported by a grant of the Deutsche Forschungsgemeinschaft [En 469/1-1]. Sabrina Bleidissel, Christiane Wallnisch, Maria Orland, Monika Kräling, and Julia Leven helped with DNA extractions, PCRs and sequencing. Kim and Nicole Schmidt assisted during the mating trials and rearing of offspring.

\section{References}

Alcock J (1994) Postinsemination associations between males and females in insects: the mateguarding hypothesis. Annu Rev Entomol 39:1-21

Aumann N (2000) Lebenslaufgeschichte und Paarungssystem der Skorpionsfliege Panorpa communis L. (Mecoptera, Insecta). Dissertation, Rheinische Friedrich-Wilhelms-Universität Bonn

Baer B, Morgan ED, Schmid-Hempel P (2001) A nonspecific fatty acid within the bumblebee mating plug prevents females from remating. Proc Natl Acad Sci USA 98:3926-3928

Birkhead TR, Hunter FM (1990) Mechanisms of sperm competition. Trends Ecol Evol 5:48-52

Birkhead TR, Møller AP (eds) (1998) Sperm competition and sexual selection. Academic Press, San Diego

Birkhead TR, Martinez JG, Burke T, Froman DP (1999) Sperm mobility determines the outcome of sperm competition in the domestic fowl. Proc R Soc Lond B 266:1759-1764

Boorman E, Parker GA (1976) Sperm (ejaculate) competition in Drosophila melanogaster, and the reproductive value of females to males in relation to female age and mating status. Ecol Entomol 1:145-155

Byers GW, Thornhill R (1983) Biology of the Mecoptera. Annu Rev Entomol 28:203-228

Cook PA, Gage MJG (1995) Effects of risks of sperm competition on the numbers of eupyrene and apyrene sperm ejaculated by the moth Plodia interpunctella (Lepidoptera, Pyralidae). Behav Ecol Sociobiol 36:261-268

Dickinson JL (1986) Prolonged mating in the milkweed beetle Labidomera clivicollis clivicollis (Cleoptera: Chrysomelidae): a test of the "sperm loading" hypothesis. Behav Ecol Sociobiol $18: 331-338$

Dziuk PJ (1996) Factors that influence the proportion of offspring sired by a male following heterospermic insemination. Anim Reprod Sci 43:65-88

Eady PE (1995) Why do male Callosobruchus maculatus beetles inseminate so many sperm? Behav Ecol Sociobiol 36:25-32

Eberhard WG (1996) Female control: sexual selection by cryptic female choice. Princeton University Press, Princeton NJ

Engqvist L, Sauer KP (2001) Strategic male mating effort and cryptic male choice in a scorpionfly. Proc R Soc Lond B 268:729-735

Engqvist L, Sauer KP (2003a) Determinants of sperm transfer in the scorpionfly Panorpa cognata: male variation, female condition and copulation duration. J Evol Biol 16:1196-1204

Engqvist L, Sauer KP (2003b) Influence of nutrition on courtship and mating in the scorpionfly Panorpa cognata. Ethology 109:911-928 
Engqvist L, Reinhold K (2006) Theoretical influence of female mating status and remating propensity on male sperm allocation patterns. J Evol Biol 19:1448-1458

Epplen C, Over I, Lubjuhn T, Epplen JT, Sauer KP (1998) Genetic distinction of scorpionflies (Panorpa vulgaris) by microsatellites. Mol Ecol 7:1256-1258

Froman DP, Pizzari T, Feltmann AJ, Castillo-Juarez H, Birkhead TR (2002) Sperm mobility: mechanisms of fertilizing efficiency, genetic variation and phenotypic relationship with male status in the domestic fowl, Gallus gallus domesticus. Proc R Soc Lond B 269:607-612

Gack C, Peschke K (1994) Spermathecal morphology, sperm transfer and a novel mechanism of sperm displacement in the rove beetle, Aleochara curtula (Coleoptera, Staphylinidae). Zoomorphology 114:227-237

Gage MJG, Morrow EH (2003) Experimental evidence for the evolution of numerous, tiny sperm via sperm competition. Curr Biol 13:754-757

Gage MJG, Stockley P, Parker GA (1995) Effects of alternative male mating strategies on characteristics of sperm production in the Atlantic salmon (Salmo salar): Theoretical and empirical investigations. Philos Trans R Soc Lond. B 350:391-399

Gage MJG, Macfarlane CP, Yeates S, Ward RG, Searle JB, Parker GA (2004) Spermatozoal traits and sperm competition in Atlantic salmon: Relative sperm velocity is the primary determinant of fertilization success. Curr Biol 14:44-47

Gerhards U, Sauer KP (1997) The mating system in the scorpionfly Panorpa germanica (Insecta: Mecoptera). Verh Dtsch Zool Ges 90:236

Gerhards U, von Zeddelmann S, Sauer KP (1999) The scorpionfly Panorpa germanica (Insecta; Mecoptera): Mating system, sperm transfer and adaptive role of the notal organ. Zoology 102 Suppl. II:27

Grell KG (1942) Der Genitaltraktus von Panorpa communis L. Ein weiterer Beitrag zur Anatomie und Histologie der Mecopteren. Zool Jahrb Abt Anat 67:513-588

Harvey IF, Parker GA (2000) 'Sloppy' sperm mixing and intraspecific variation in sperm precedence $\left(\mathrm{P}_{2}\right)$ patterns. Proc R Soc Lond B 267:2537-2542

Ihaka R, Gentleman R (1996) R: A language for data analysis and graphics. J Comput Graph Statist 5:299-314

Kock D, Hardt C, Epplen JT, Sauer KP (2006) Patterns of sperm use in the scorpionfly Panorpa germanica L. (Mecoptera: Panorpidae). Behav Ecol Sociobiol 60:528-535

Lewis SM, Austad SN (1990) Sources of intraspecific variation in sperm precedence in red flour beetles. Am Nat 135:351-359

Lubjuhn T, Sauer KP (1999) DNA Fingerprinting and profiling in behavioural ecology. In: J. T. Epplen, Lubjuhn T (eds) DNA Profiling and DNA Fingerprinting. Birkhäuser Verlag, Basel, pp 39-52

Martin OY, Hosken DJ (2002) Strategic ejaculation in the common dung fly Sepsis cynipsea. Anim Behav 63:541-546

Morrow EH, Gage MJG (2001) Sperm competition experiments between lines of crickets producing different sperm lengths. Proc R Soc Lond B 268:2281-2286

Parker GA (1970) Sperm competition and its evolutionary consequences in the insects. Biol Rev 45:525-567

Parker GA (1982) Why are there so many tiny sperm? Sperm competition and the maintenance of two sexes. J Theor Biol 96:281-294

Parker GA, Simmons LW, Kirk H (1990) Analysing sperm competition data: simple models for predicting mechanisms. Behav Ecol Sociobiol 27:55-65

Parker GA, Ball MA, Stockley P, Gage MJG (1997) Sperm competition games: a prospective analysis of risk assessment. Proc R Soc Lond B 264:1793-1802

Pinheiro JC, Bates DM (2000) Mixed effects models in S and S-plus. Springer, New York

Polak M, Wolf LL, Starmer WT, Barker JSF (2001) Function of the mating plug in Drosophila hibisci Bock. Behav Ecol Sociobiol 49:196-205

Radwan J (1996) Intraspecific variation in sperm competition success in the bulb mite: a role for sperm size. Proc R Soc Lond B 263:855-859

Radwan J (1998) Heritability of sperm competition success in the bulb mite, Rhizoglyphus robini. J Evol Biol 11:321-327

Sakaluk SK, Eggert A-K (1996) Female control of sperm transfer and intraspecific variation in sperm. Evolution 50:694-703

Sauer KP (1977) The adaptive significance of genetic variability of photoperiodic response in Panorpa vulgaris. Zool Jahrb Syst 104:489-538

Sauer KP (1996) Sexual selection and ecological differentiation. J Zool Syst Evol Res 34:235-249 
Sauer KP, Riebel W, Bockwinkel G (1990) Einfluß von Reihenfolge und Kopulationsdauer der Männchen von Panorpa vulgaris (Mecoptera) auf die Vaterschaft. Verh Dtsch Zool Ges 83:656657

Sauer KP, Sindern J, Kall N (1997) Nutritional status of males and sperm transfer in the scorpionfly Panorpa vulgaris (Mecoptera: Panorpidae). Entomol Gener 21:189-204

Sauer KP, Lubjuhn T, Sindern J, Kullmann H, Kurtz J, Epplen C, Epplen JT (1998) Mating system and sexual selection in the scorpionfly Panorpa vulgaris (Mecoptera: Panorpidae). Naturwissenschaften 85:219-228

Sauer KP, Epplen C, Over I, Lubjuhn T, Schmidt A, Gerken T, Epplen JT (1999) Molecular genetic analysis of remating frequencies and sperm competition in the scorpionfly Panorpa vulgaris (Imhoff and Labram). Behaviour 136:1107-1121

Siegmund BW (2006) Sperm competition in the scorpionfly Panorpa communis (Mecoptera, Insecta). Dissertation, Rheinische Friedrich-Wilhelms-Universität Bonn

Simmons LW (2001) Sperm competition and its evolutionary consequences in the insects. Princeton University Press, Princeton NJ

Simmons LW, Siva-Jothy MT (1998) Sperm competition in insects: mechanisms and the potential for selection. In: Birkhead TR, Møller AP (eds) Sperm competition and sexual selection. Academic Press, San Diego, pp 341-434

Siva-Jothy MT, Stutt AD (2003) A matter of taste: direct detection of female mating status in the bedbug. Proc R Soc Lond B 270:649-652

Snook RR (2005) Sperm in competition: not playing by the numbers. Trends Ecol Evol 20:46-53

Stockley P, Seal NJ (2001) Plasticity in reproductive effort of male dung flies (Scatophaga stercoraria) as a response to larval density. Funct Ecol 15:96-102

Thornhill R (1979) Male pair-formation pheromones in Panorpa scorpionflies (Mecoptera: Panorpidae). Environ Entomol 8:886-888

Thornhill R (1981) Panorpa (Mecoptera: Panorpidae) scorpionflies: systems for understanding resource-defense polygyny and alternative male reproductive efforts. Ann Rev Ecol Syst 12:355386

Thornhill R (1983) Cryptic female choice and its implications in the scorpionfly Harpobittacus nigriceps. Am Nat 122:765-788

Thornhill R, Sauer KP (1992) Genetic sire effects on the fighting ability of sons and daughters and mating success of sons in a scorpionfly. Anim Behav 43:255-264

Tsubaki Y, Sokei Y (1988) Prolonged mating in the melon fly, Dacus cucurbitae (Diptera: Tephritidae): competition for fertilization by sperm-loading. Res Popul Ecol 30:343-352

Tsubaki Y, Yamagishi M (1991) Longevity of sperm within the female of the Melon fly, Dacus cucurbitae (Diptera, Tephritidae), and its relevance to sperm competition. J Insect Behav 4:243250

Venables WN, Ripley BD (2002) Modern applied statistics with S, 4th edn. Springer, New York

Waage JK (1979) Dual function of the damselfly penis: sperm removal and transfer. Science 203:916918

Walker WF (1980) Sperm utilization strategies in nonsocial insects. Am Nat 115:780-799

Ward PI (1998) Intraspecific variation in sperm size characters. Heredity 80:655-659

Wedell N (1998) Sperm protection and mate assessment in the bushcricket Coptaspis sp. 2. Anim Behav 56:357-363 